\title{
Control of Black Carbon, the Most Effective Means of Slowing Global Warming
}

\author{
Mark Z. Jacobson \\ Department of Civil and Environmental Engineering \\ Stanford University Terman Engineering Center, Room M-13 \\ Stanford, CA 94305-4020 Phone: 650-723-6836 Fax: 650-725-9720 \\ jacobson@ce.stanford.edu
}

\begin{abstract}
Under the Kyoto Protocol of 1997, no control of black carbon (BC) was considered. Recent studies, though, have suggested that BC and non-CO2 greenhousegas emission controls might slow global warming. Yet, no study has compared the effects, over time, of theoretically reducing $\mathrm{BC}$ versus $\mathrm{CO} 2$ or $\mathrm{CH} 4$ emissions. In this study, a global model was used to compare the effects of such reductions. The model treated eight important feedbacks of aerosols to climate. Results suggest that the most efficient method of controlling global warming over the next 20-50 years, in terms of the magnitude and speed of a cooling, is control of fossilfuel BC and associated organic matter. It is further shown that late-model diesel vehicles enhance global warming more than do equivalent gasoline vehicles, yet fuel-tax and carbon-tax laws favor diesel in many countries. It is concluded that control strategies for global warming should include control of BC along with control of $\mathrm{CO} 2$ and other greenhouse gases.
\end{abstract}

V.N. Alexandrov et al. (Eds.): ICCS 2001, LNCS 2074, p. 1060, 2001.

(c) Springer-Verlag Berlin Heidelberg 2001 